CLINICAL STUDY

\title{
Health-related quality of life in acromegalic subjects: data from AcroBel, the Belgian Registry on acromegaly
}

\author{
Guy T’Sjoen, Marie Bex ${ }^{1}$, Dominique Maiter ${ }^{2}$, Brigitte Velkeniers ${ }^{3}$ and Roger Abs ${ }^{4}$ \\ Department of Endocrinology, Ghent University Hospital, De Pintelaan 185, 9000 Gent, Belgium, ${ }^{1}$ Department of Endocrinology, UZ Leuven, Herestraat \\ 49, 3000 Leuven, Belgium, ${ }^{2}$ Department of Endocrinology, UCL St Luc Brussels, Avenue Hippocrate 10, 1200 Brussels, Belgium, ${ }^{3}$ Department of \\ Endocrinology, AZ VUB Brussels, Laarbeeklaan 101, 1090 Brussels, Belgium and ${ }^{4}$ Department of Endocrinology, University of Antwerp, Wilrijkstraat \\ 10, 2650 Edegem, Belgium
}

(Correspondence should be addressed to G T'Sjoen; Email: guy.tsjoen@ugent.be)

\begin{abstract}
Objective: To assess the impairment of quality of life (QoL), evaluated by the acromegaly QoL (AcroQoL) questionnaire, in patients with controlled and uncontrolled acromegaly.

Design: Cross-sectional evaluation of AcroBel, a national observational registry of acromegalic patients newly diagnosed or in follow-up.

Methods: Disease perception by the patients was evaluated by the disease-specific signs and symptoms score (SSS) and QoL was assessed by the AcroQoL questionnaire. Hormonal status was determined by central measurements of GH and IGF-I.

Results: Patients $(n=291)$ had a median GH of $1.43 \mu \mathrm{g} / \mathrm{l}(0.65-3.03$; IQR), a median IGF-I of $231 \mu \mathrm{g} / \mathrm{l}$ (150-367), and a mean IGF-I z-score of +1.91 (s.D. 2.21). The AcroQoL total score in the whole group was 67.1 (51.1-78.4), with a score of $65.6(43.8-78.1)$ for the physical dimension, 67.9 (53.6-80.4) for the psychological dimension, 78.6 (64.3-89.3) for personal relations and 57.1 (39.3-75) for appearance. The median SSS was 3 (1-5). There was a negative correlation between both questionnaires $(r=-0.478 ; P<0.001)$. There was no correlation between AcroQoL score and biochemical markers of disease activity. When subdividing patients into groups of biochemical control according to GH and IGF-I levels, no difference could be established for either SSS or AcroQoL scores. Conclusions: The AcroQoL results from the AcroBel registry confirm the marked impairment of the patients' QoL, especially in relation with appearance. A negative correlation between AcroQoL and SSS was confirmed. There was, however, no correlation between AcroQoL and biochemical markers of disease activity.
\end{abstract}

European Journal of Endocrinology 157 411-417

\section{Introduction}

Acromegaly is a rare disease usually caused by a growth hormone (GH)-secreting pituitary adenoma $(1,2)$. Because of the slowly progressing nature of the disorder, the diagnosis is often delayed while prolonged exposure to excessive serum concentrations of $\mathrm{GH}$ and insulin-like growth factor I (IGF-I) continues to affect morbidity and quality of life $(\mathrm{QoL})(3-5)$. Biochemical control is more easily achieved nowadays due to improvements in surgical techniques and medical treatment. Neurosurgery and drug therapy with somatostatin analogues have been shown to improve general health and health-related QoL (HR QoL) in acromegalic patients (6). However, data on mental and emotional dysfunction and QoL during treatment are limited. The therapeutic assessment of acromegaly has mostly been focussed on the hormonal control and tumour shrinkage, and less on the associated symptoms and morbidities (5). Moreover, patients report an enduring impairment of well-being as a consequence of lasting cosmetic and orthopaedic deformities despite normalisation of GH/IGF-I secretion $(7,8)$.

The primary objective of this project was to assess the impact of acromegaly on the symptoms and signs score (SSS) and on QoL evaluated by the Acromegaly QoL (AcroQoL) questionnaire in 291 acromegalic patients enlisted in AcroBel, the Belgian registry for acromegaly, which presently comprises a total of 418 acromegalic patients with controlled and uncontrolled disease.

\section{Subjects and methods}

\section{Subjects}

AcroBel is the registry on acromegaly established to recruit and assess the Belgian acromegalic subjects newly diagnosed or in follow-up between January 1st, 2000 and September 30th, 2004. The primary 
objectives of AcroBel are to describe the demography and epidemiology of acromegaly in Belgium and to evaluate the quality of care. Details of the design of AcroBel are extensively documented in a companion paper (9).

A total of 418 acromegalic patients were included in the registry, of which 362 actively participated in a cross-sectional evaluation. Questionnaires related to QoL were obtained from 308 subjects. Incomplete laboratory results $(n=3)$, GH replacement therapy $(n=10)$ or use of pegvisomant $(n=4)$ were exclusion criteria for this study, which was restricted to 291 patients. At the survey visit, demographic variables (age, gender, height and weight) as well as diagnostic information (initial tumour size, co-secretion, pituitary deficiencies, acromegalic co-morbidities, previous and current treatment and follow-up time from diagnosis) were recorded. The study protocol had been approved by the Ethics Committee of the University Hospital of Leuven, and written informed consent was obtained from all participants.

\section{Determination and evaluation of hormonal variables}

Blood was sampled in fasting conditions for centralised determinations of IGF-I (one sample) and GH (as a mean of three values, taken at intervals of $15 \mathrm{~min}$ ). These samples were frozen at $-80{ }^{\circ} \mathrm{C}$ in the individual centres for later transport to the central laboratory (UCL Saint Luc, Brussels, Belgium). Serum GH and IGF-I concentrations were determined by automated immunoassays (Advantage, Nichols Institute, San Juan Capistrano, CA, USA). The sensitivity of the GH assay was $0.1 \mu \mathrm{g} / \mathrm{l}$ and the intra- and inter-assay coefficients of variation were 4.8 and $5.8 \%$ respectively. GH values were expressed in terms of the first WHO International Standard (IS) $80 / 505$ for pituitary-derived $\mathrm{GH}$, in use at that time (conversion factor for expression in terms of the new WHO IS $98 / 574=\mathrm{GH}$ concentration $\times 0.56$ ). The sensitivity of the IGF-I assay was $6 \mu \mathrm{g} / \mathrm{l}$ and the intraand inter-assay coefficients of variation were 5.2 and $5.7 \%$ respectively. All measurements were completed at the end of the survey period in two consecutive runs for $\mathrm{GH}$ and in one run for IGF-I. IGF-I values were compared with age- and gender-specific reference ranges (10) and were expressed as a $z$-score (normal range -2 to +2$)$.

The central lab IGF-I and mean GH values defined the assignment to an outcome group. Cure was defined by the strict criteria of both a normal IGF-I for age and gender $(z$-score $\leq 2)$ and a mean $\mathrm{GH}$ value $\leq 2 \mu \mathrm{g} / \mathrm{l}$ following surgery and/or radiotherapy. Controlled disease was defined by the same strict criteria when obtained under medical therapy irrespective of previous surgery or radiotherapy. Active disease was defined by an IGF-I $z$-score 2 and a mean GH value $2 \mu \mathrm{g} / \mathrm{l}$. Patients with discordant IGF-I and
GH values were also considered to have active disease, with the exception of operated patients with a strictly normal IGF-I and a mean GH $2 \mu \mathrm{g} / \mathrm{l}$ but documentation of a $\mathrm{GH}$ nadir after an oral glucose tolerance test (OGTT) $1 \mu \mathrm{g} / \mathrm{l}$ or a random $\mathrm{GH}$ at least once below the detection limit of $0.5 \mu \mathrm{g} / \mathrm{l}$. HbAlc was analysed according to local standard methods (normal values $3-6 \%$ ).

\section{Questionnaires}

AcroQoL The AcroQoL questionnaire contains 22 items divided into two scales, of which one evaluates physical features (8 items) and the other assesses psychological aspects (14 items). The latter is further divided into two subscales: one measuring appearance-related characteristics (7 items) and the other evaluating the impact of disease on personal relationships (7 items) $(11,12)$.

Each of the 22 items is answered in a 1 (worse) to 5 (best) Likert scale, reflecting either the frequency of occurrence (always, most of the time, sometimes, rarely and never) or the degree of agreement with the item (completely agree, moderately agree, neither agree nor disagree, moderately disagree and completely disagree). A global score and scores of the respective scales and subscales are obtained by completing the results using the following formula: $((X-Y) /(5 Y-Y)) \times 100$ where $X$ is the sum of the answers (between 1 and 5 for each item) of the respective scale and $Y$ is the number of items of the respective scale. The formula converts the different scores to a scale between a minimum of 0 to a maximum of 100, where a higher score indicates a better QoL. If the percentage of unanswered questions does not exceed $25 \%$, a score is considered as calculable. No reference values are provided

The original Spanish questionnaire has been translated into Dutch and French, two of the official languages of Belgium, following the recommended standard methodology. In patients with stable acromegaly, no difference was observed on retesting at 1 month, thus demonstrating a good test-retest reliability (13) and internal consistency. Validity has been established in several studies $(5,7,14)$. Results of AcroQoL were also shown to be consistent across different European countries (15).

Signs and symptoms score (SSS) The SSS is a diseasespecific tool that rates five features of acromegaly: headache, excessive perspiration, arthralgia, fatigue and soft tissue swelling, scoring 0-3 for each of the items. The maximum score $(=15)$ is indicative of severe incapacitating signs and symptoms. SSS has a limited focus on the most reversible aspects of acromegaly; therefore, this score is not a measure of QoL. 
Data analysis Descriptive statistics are given as means and S.D.s or medians and interquartile (IQR) ranges. Normal distribution of continuous variables was tested by means of the Kolmogorov-Smirnov test. Pearson's and Spearman's correlation coefficients were calculated for studying associations between study variables. The independent sample $t$-test and the non-parametric Mann-Whitney test were used to compare study variables between two groups. One way ANOVA and non-parametric Kruskall-Wallis test were used to compare the four different groups according to $\mathrm{GH}$ and IGF-I levels. A level of $\alpha=0.05$ was chosen to indicate statistical significance. Cronbach's $\alpha$ was calculated to estimate the degree of internal consistency of the questionnaires and was always 0.70 , which reflects good reliability.

Stepwise linear regression analysis was used to study factors related to AcroQoL within the survey population. All analyses were performed using SPSS software (version 12.0; SPSS Inc., Chicago, IL, USA).

\section{Results}

\section{Clinical characteristics}

The study cohort included 291 acromegalic patients ( $51 \%$ males) with a mean age of 54.8 years at the time of the survey. A macroadenoma was reported in 237 patients $(81 \%)$, a microadenoma in 42 patients $(14 \%)$, adenoma of unknown size in 11 patients $(4 \%)$ and a GH-releasing hormone (GHRH)-producing carcinoid in 1 patient. A pure $\mathrm{GH}$-secreting adenoma was reported in 202 patients $(70 \%)$ and prolactin co-secretion in 69 patients $(24 \%)$, while co-secretion of other hormones ( $\alpha$-subunit and/or thyroid-stimulating hormone) was reported twice and tumour type was unspecified in 15 cases. Pituitary function apart from GH secretion was preserved in 169 patients (58\%), while at least one pituitary deficiency was seen in 120 patients $(41 \%)$.

The most frequent reported morbidity was arthropathy $(42 \%)$, followed by hypertension $(39 \%)$, carpal tunnel syndrome $(27 \%)$, diabetes mellitus $(23 \%)$ and goitre $(21 \%)$.

Treatment modalities had been surgery $(n=116$, $40 \%)$, radiotherapy $(n=18,6 \%)$, combined surgery and radiotherapy $(n=82,28 \%)$ or primary drug therapy only $(n=71,24 \%)$. Presently, 185 patients $(64 \%)$ were on medical treatment, either with somatostatin analogues $(n=134,46 \%)$ or dopamine agonists $(n=39$, $13 \%)$, or combination of both $(n=12,4 \%)$. Median follow-up time from diagnosis was 10 years (5-17).

\section{Hormonal data}

For the whole cohort, median GH was $1.43 \mu \mathrm{g} / \mathrm{l}$ (0.65-3.03; IQR), median IGF-I was $231 \mu \mathrm{g} / \mathrm{l}$ (150-367) and the mean IGF-I $z$-score was +1.91 (s.D. 2.21; Table 1). The IGF-I $z$-score correlated with the age at diagnosis $(r=0.190, P=0.001)$. Overall, the median $\mathrm{HbAlc}$ level was in the normal range $(5.8 \%$ (5.5-6.2)) reflecting adequate glycemic control in a majority of patients.

Taking the above mentioned criteria into account, patients were categorised as being cured $(n=72)$ or controlled $(n=67)$ having active disease $(n=77)$ or discordant GH and IGF-I values $(n=75)$.

Table 1 Descriptive, laboratory and questionnaire results of the AcroBel group.

\begin{tabular}{|c|c|c|c|c|c|}
\hline & $N$ & Mean & S.D. & Median & IQR \\
\hline \multicolumn{6}{|l|}{ Patient data } \\
\hline Age at diagnosis $(y)$ & 291 & 43.0 & 13.1 & 42.0 & $34.0-52.0$ \\
\hline Age at survey $(y)$ & 291 & 54.8 & 13.5 & 55.0 & $44.0-65.0$ \\
\hline Follow-up duration & 291 & 11.8 & 9.0 & 10.0 & $5.0-17.0$ \\
\hline Body mass index & 289 & 28.9 & 5.2 & 28.3 & $24.6-31.8$ \\
\hline \multicolumn{6}{|l|}{ Hormonal data } \\
\hline $\mathrm{GH}(\mu \mathrm{g} / \mathrm{l})$ & 291 & 3.05 & 5.25 & 1.43 & $0.65-3.03$ \\
\hline z-IGF-1 & 291 & 1.91 & 2.12 & 1.79 & $0.58-3.34$ \\
\hline IGF-I ( $\mu \mathrm{g} / \mathrm{I})$ & 291 & 297.9 & 221.3 & 230.6 & $149.5-367.1$ \\
\hline $\mathrm{HbA1c}(\%)$ & 272 & 5.9 & 0.9 & 5.8 & $5.5-6.2$ \\
\hline \multicolumn{6}{|l|}{ AcroQoL } \\
\hline Physical & 289 & 60.88 & 23.73 & 65.6 & $43.8-78.1$ \\
\hline Psychological & 280 & 65.42 & 19.30 & 67.9 & $53.6-80.4$ \\
\hline Relations & 270 & 74.48 & 19.48 & 78.6 & $64.3-89.3$ \\
\hline Appearance & 284 & 56.78 & 22.93 & 57.1 & $39.3-75.0$ \\
\hline Total score & 285 & 63.85 & 19.32 & 67.1 & $51.1-78.4$ \\
\hline \multicolumn{6}{|l|}{ SSS } \\
\hline Sweating & 289 & 0.6 & 0.9 & 0 & $0-1$ \\
\hline Swelling soft tissue & 289 & 0.5 & 0.8 & 0 & $0-1$ \\
\hline Headaches & 289 & 0.5 & 0.8 & 0 & $0-1$ \\
\hline Fatigue & 289 & 0.9 & 0.9 & 1 & $0-2$ \\
\hline Joint pain & 289 & 0.8 & 0.9 & 0 & $0-1$ \\
\hline Total score & 289 & 3.3 & 2.9 & 3 & $1-5$ \\
\hline
\end{tabular}




\section{AcroQoL data}

The median AcroQoL total score for the whole group was 67.1 (51.1-78.4; IQR). The score for the physical dimension was $65.6(43.8-78.1)$ and was negatively related to $\mathrm{HbA1c}(r=-0.134, P=0.028)$. For the psychological dimension, the median score was 67.9 (53.6-80.4), with better results for personal relations (78.6 (64.3-89.3)) and worse results for appearance (57.1 (39.3-75)). Lower AcroQoL physical scores were reported by females when compared with males $(P=0.016$; Fig. 1$)$.

Age, height, weight at survey, tumour size, co-secretion, presence of hypertension and diabetes mellitus or treatment modality were not significantly associated with any of the AcroQoL scores, except for a correlation between the physical score and height $(r=0.172$, $P=0.003)$. No difference between age groups could be established for AcroQoL total or subscores (Fig. 1). The presence of at least one pituitary deficit was associated with lower scores for psychological and relational items $(P=0.019$ and 0.002 respectively), while radiotherapy was not significantly related to the AcroQoL score $(P=0.098)$. A borderline negative correlation was found between the AcroQoL personal relation score and follow-up time from diagnosis $(r=-0.122$, $P=0.046)$. In a linear regression model, a higher total score for AcroQoL was predicted by male gender $(\beta=5.650, \mathrm{SE}=2.445, P=0.022)$, lower body mass index (BMI) $(\beta=-0.596, \mathrm{SE}=0.224, P=0.015)$ and
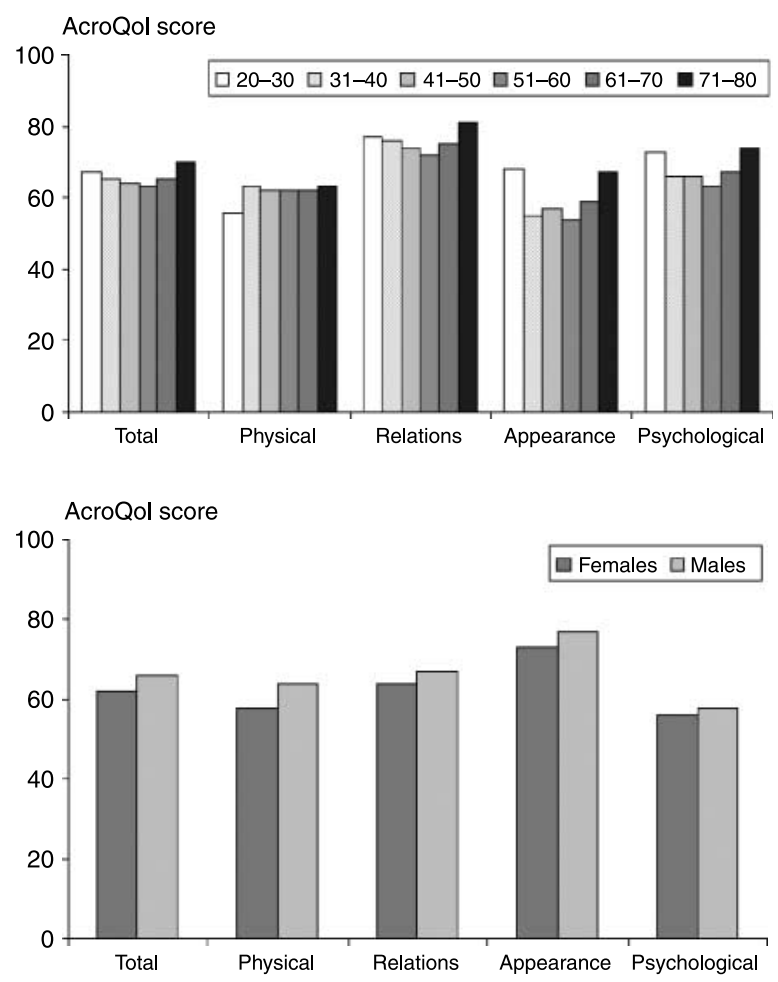

Figure 1 AcroQoL total and subscores according to age and gender. Bars show means. lower HbA1c $(\beta=-2.634$, SE $=1.285, P=0.041$; Fig. 2). The parameters included in the analysis were age at survey, gender, BMI, hypertension, diabetes mellitus, pituitary deficiencies, tumour size, radiotherapy, medication and surgery.

There was no significant relation between the AcroQoL score and the biochemical markers of disease activity. Moreover, when dividing patients in the four groups according to their GH and IGF-I levels no difference could be established for AcroQoL scores ( $P$ values between 0.216 and 0.856 ; Table 2 ).

\section{Signs and symptoms score (SSS)}

The median SSS was 3 (1-5). The IGF-I $z$-score correlated with the total SSS $(r=0.126, P=0.031)$, and with some of the individual items, such as soft tissue swelling $(r=0.165, P=0.005)$ and sweating $(r=0.123, P=0.036)$. However, when dividing patients in the four groups according to their GH and IGF-I levels, no differences between groups were found for either total SSS $(P=0.059)$ and subscores $(P$ between 0.187 and 0.434), with the exception of "soft tissue swelling', which was scored higher by the patients with active disease $(P=0.024)$.

There was no relation between the total SSS and the age of the patients, although the 'joint pain' score was related to age $(r=0.179, P=0.002)$. Females had higher headache and fatigue scores than males $(P=0.005$ and $P=0.028$ respectively). The symptom 'excessive perspiration' was associated with a higher body weight $(r=0.207, P=0.001)$. None of the other tested variables in demographic parameters or diagnostic information were related to the total SSS or subscores. HbAlc was related to the total SSS

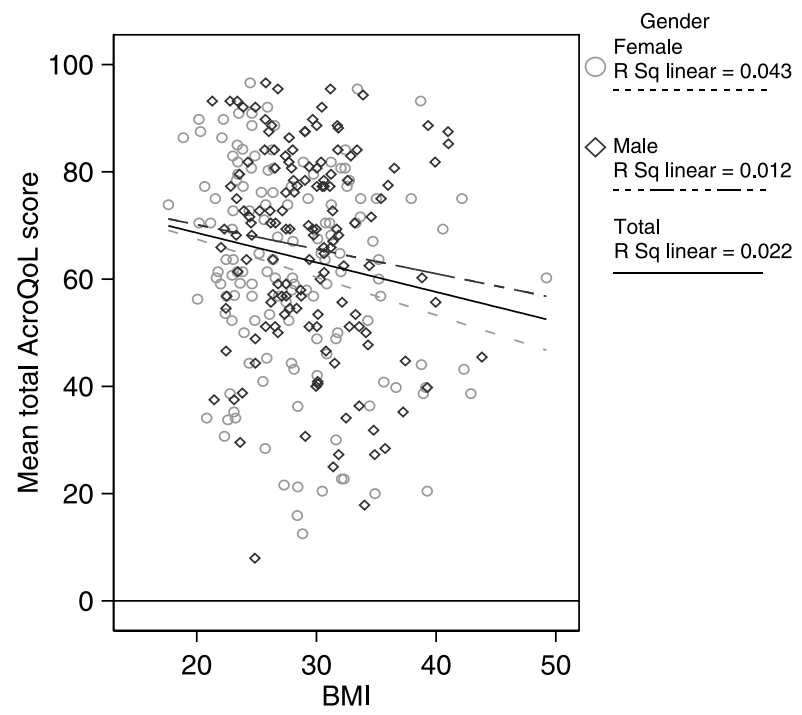

Figure 2 Linear regression analysis indicated that a higher AcroQoL total score was predicted by lower BMI $(P=0.015)$ and by male gender $(P=0.022)$. 
Table 2 Acromegaly quality of life (AcroQoL) total and subscores according to outcome group based upon insulin-like growth factor I (IGF-I) and growth hormone $(\mathrm{GH})$ values.

\begin{tabular}{|c|c|c|c|c|c|c|}
\hline & $N$ & Physical score & $\begin{array}{l}\text { Psychological } \\
\text { score }\end{array}$ & Relations score & $\begin{array}{l}\text { Appearance } \\
\text { score }\end{array}$ & Total score \\
\hline Cured & 72 & $62.5(43.8-81.3)$ & $69.2(53.6-78.7)$ & $75.0(64.3-85.7)$ & $57.1(42.9-75.0)$ & $64.8(51.7-79.0)$ \\
\hline Controlled & 67 & $59.4(46.4-71.8)$ & $64.3(48.7-81.7)$ & 78.6 (58.9-89.3) & $53.9(35.7-75.0)$ & $61.4(45.5-77.3)$ \\
\hline Active disease & 77 & $65.6(44.4-78.1)$ & $71.4(50.0-82.1)$ & 78.6 (67.9-89.3) & $60.7(31.3-75.9)$ & $65.9(52.0-80.7)$ \\
\hline Discordant GH/IGF-I & 75 & $68.8(43.8-81.3)$ & $67.9(56.7-80.4)$ & $82.1(67.9-89.3)$ & $54.2(42.9-78.6)$ & $70.5(56.8-79.5)$ \\
\hline$P$ between groups & & 0.575 & 0.856 & 0.216 & 0.743 & 0.535 \\
\hline
\end{tabular}

Median and interquartile ranges are shown. $P$ values for non-parametric Kruskall-Wallis test to compare between groups.

$(r=0.163, P=0.007)$, fatigue $(r=0.143, P=0.019)$ and joint pain score $(r=0.128, P=0.035)$.

There was a negative correlation between the median SSS and the median AcroQoL total score in the whole study population $(r=-0.478 ; P<0.001)$.

\section{Discussion}

The primary objective of this study was to assess the impact of acromegaly control on the clinical status perceived by the patient, measured by the SSS questionnaire, and on the QoL, evaluated by the AcroQoL questionnaire, using the Belgian observational registry AcroBel (9). Since this survey illustrates real life conditions of diagnosis, treatment and outcome of acromegaly, our study population is different from those of other European surveys mainly concentrating on large centres with experience in the management of acromegaly (16-18). In addition, AcroBel survey offers the advantage of relying on centralised biochemical outcome parameters.

AcroQoL is the first disease-generated instrument to specifically assess dimensions of HRQoL most likely to be affected in patients with acromegaly (11). It is a diseaseoriented questionnaire containing items designed for this particular condition with the purpose to assess the self-perceived status and to allow evaluation of interventions, but also to identify patients who possibly require further treatment. Reference values are not yet available. Moreover, in cross-sectional studies, AcroQoL results have been shown not to relate to biochemical measures of disease control $(5,14)$. However, in a 6-month follow-up study, AcroQoL was responsive to changes following medical or surgical treatment, and improvement in the global score of AcroQoL was related to a global improvement in HRQoL (12). In a prospective 6 months intervention study, the AcroQoL score improved significantly with treatment, but without correlation between the questionnaire and changes in GH or IGF-I (5). In the study by Paisley et al. 56 acromegalic patients were re-evaluated after a median interval of 532 days (19). Decrease in IGF-I resulted in an improvement in overall QoL as measured by AcroQoL total score and all dimensions. Another prospective study, only published in abstract form, described a good correlation between AcroQoL and short form-36 in acromegalic patients treated with Sandostatin LAR (15). This is the first study to report on the use of AcroQoL in a nationwide registry with controlled and uncontrolled patients. Median AcroQoL total and subscores are comparable with those reported earlier for acromegalic patients in remission $(5,7,14$, $20,21)$, and higher than that in active acromegaly (5-20).

The current study was cross sectional in design, with 10 years disease span on average, allowing an appreciation of the long-term influence of acromegaly upon the development of co-morbidities and the perception of health by the patient. Despite a satisfactory overall degree of biochemical control in our study group (22), QoL evaluated by AcroQoL was significantly impaired, confirming previous studies (14, 23). While biochemical or radiological markers of the disease and mortality rate have the opportunity of being measurable, it is obvious that from the patient's perspective well-being is an important outcome.

Other studies have demonstrated the marked and prolonged influence of acromegaly on the patient's QoL $(14,18)$. In the study by Rowles et al. (14), the AcroQoL-physical dimension correlated with SSS in patients with active disease. Our study confirms the marked impact of appearance on HRQoL, and a lesser impairment of the personal relations score, as previously reported by Webb et al. $(5,21)$. In the study of Biermasz et al. comprising 118 acromegalic patients in long-term remission, joint problems had a significant negative impact on QoL, including AcroQoL total and all subscores (7). In view of the disabling and disfiguring effects of acromegaly, we may hypothesise that the persistence of cosmetic and orthopaedic deformities independent of the levels of GH and IGF-I could be responsible for the lack of difference in QoL when comparing groups with different degrees of biochemical control (8).

No relationship was found in our study between either GH or IGF-I concentrations and AcroQoL, and there was no difference in QoL score between patients with active and inactive disease, confirming the data by Rowles et al. (14) and Hua et al. (24). In contrast, in the study by Trepp et al., patients with uncontrolled acromegaly had significant lower HRQoL than patients 
in remission or with a discordant remission status (20). However, this was a single-centre study with rather small numbers of patients. When measured with the generic 15D instrument, HRQoL was related to $\mathrm{GH}$ suppression after an oral glucose tolerance test in an inverted U-shaped fashion (18).

The SSS is not a measure of HRQoL but was specifically designed to evaluate the severity of reversible symptoms associated with GH hypersecretion (6). In cross-sectional studies, the SSS has also been shown not to relate to biochemical measures of disease control (14). Prospective intervention trials aiming at reducing serum IGF-I concentrations have shown concomitant reduction in this score, with significant decreases in scores for soft-tissue swelling, excessive perspiration, fatigue and in the total score, with the greatest biochemical response experiencing the greatest improvement in SSS (25). In the current study, SSS results did not correlate with serum GH and IGF-I concentrations, but the IGF-I $z$-score correlated positively with the total SSS and with some of the individual items such as soft tissue swelling and sweating.

The potential for observing a relationship between biochemical parameters and QoL in our patients may be impaired by the fact that co-morbidities related to acromegaly influence QoL, as the frequent occurrence of arthropathy or may differently be influenced by the therapeutic modalities. Indirect factors, such as income, family support, housing, education, personality, environment, freedom, etc. are also likely to impact on QoL. Other relevant limitations of this paper should be mentioned. Variability of HRQoL over time is not taken into account, because of the cross-sectional nature of the design. Recently, published data, however, confirm a good test-retest reliability of the AcroQoL (13).

Younger age correlated with better HRQoL in the study by Kauppinen (18) and Biermasz (7), but not in the present study. We found that having at least one pituitary deficiency had a significant effect on the psychological dimension of the AcroQoL questionnaire, while radiotherapy had no impact. This is in contrast with other studies where radiotherapy but not the presence of hypopituitarism was related to reduced QoL $(14,18)$. There is no clear explanation for such discrepancies, even though one could suspect a relation between both of these parameters.

Significant independent parameters for AcroQoL in the present study were gender, BMI and $\mathrm{HbAlc}$. It is difficult to compare these results with data from other studies, as different specific variables have been included in the analyses or populations were different. Also, in this study, a higher $\mathrm{HbAlc}$ was associated with lower scores of the physical dimension of QoL. This relationship between $\mathrm{HbAlc}$ and impairment of QoL in patients with acromegaly, as well as the associations between $\mathrm{HbAlc}$ and the total SSS, fatigue and joint pain scores require further study and do not prove that poorer glycemic control is the cause of impaired QoL. Clearly, a larger sample size by integration of the available national registries might help to confirm or deny these different associations.

In conclusion, the AcroQoL results from the AcroBel study validate the marked impact of acromegaly on patient's QoL, especially on physical dimension and appearance. A close consistent negative correlation between AcroQoL and SSS was also confirmed. However, there was no correlation observed between AcroQoL and biochemical markers of disease activity in this cross-sectional evaluation of controlled and uncontrolled patients.

\section{Acknowledgements}

The AcroBel survey was made possible due to an unrestricted grant from Novartis Belgium and the logistical help of Mrs Katja Muermans, Novartis Belgium. We also express our gratitude to Els Feyen for statistical assistance and to all Belgian endocrinologists participating in this survey.

The following investigators contributed to the database: Pascale Abrams, Roger Abs, Orsalia Alexopoulou, Herman Becq, Annemie Beirinckx, Marie Bex, Roger Bouillon, Vincent Col, Ides Colin, Jean-Luc Coolens, Bernard Corvilain, Etienne Couturier, JeanClaude Daubresse, Etienne Delgrange, Anne-Sophie Dramais, Jean Ducobu, Françoise Fery, Yves Kockaerts, Georges Krzentowski, Gerard Lamberigts, Claude Lemy, Dominique Maiter, Georges Michel, Jean Mockel, Daniel Nicolaij, Frank Nobels, Marie-Christine Pelckmans, Kris Poppe, Carla Righes, Robert Rubens, Denis Scarnière, Jos Tits, Guy T'Sjoen, Christel Tuyttens, Paul Van Crombrugge, Annick Van den Bruel, Sylva Van Imschoot, Dirk Van Nimmen, Mark Vandeweghe, JeanFrançois Vanderijst, Etienne Vanfleteren, Brigitte Velkeniers, Chris Vercammen, Ann Verhaegen, Margaretha Verhaert, Johan Verhelst, Wouter Vinck.

\section{References}

1 Melmed S. Medical progress: acromegaly. New England Journal of Medicine $20063552558-2573$.

2 Colao A, Ferone D, Marzullo P \& Lombardi G. Systemic complications of acromegaly: epidemiology, pathogenesis, and management. Endocrine Reviews 200425 102-152.

3 Holdaway IM, Rajasoorya RC \& Gamble GD. Factors influencing mortality in acromegaly. Journal of Clinical Endocrinology and Metabolism $200489667-674$.

4 Puder JJ, Nilavar S, Post KD \& Freda PU. Relationship between disease-related morbidity and biochemical markers of activity in patients with acromegaly. Journal of Clinical Endocrinology and Metabolism $2005901972-1978$.

5 Webb SM, Badia X, Surinach NL \& Spanish AcroQol Study Group. Validity and clinical applicability of the acromegaly quality of life questionnaire, AcroQoL: a 6-month prospective study. European Journal of Endocrinology 2006155 269-277. 
6 Lamberts SW, Krenning EP, Klijn JG \& Reubi JC. The clinical use of somatostatin analogues in the treatment of cancer. Baillière's Clinical Endocrinology and Metabolism 19904 29-49.

7 Biermasz NR, Pereira AM, Smit JW, Romijn JA \& Roelfsema F. Morbidity after long-term remission for acromegaly: persisting joint-related complaints cause reduced quality of life. Journal of Clinical Endocrinology and Metabolism $2005902731-2739$.

8 Pantanetti P, Sonino N, Arnaldi G \& Boscaro M. Self image and quality of life in acromegaly. Pituitary 20025 17-19.

9 Bex M, Abs R, T'Sjoen G, Mockel J, Velkeniers B \& Maiter D. AcrobBel - the Belgian resistry on acromegaly. A survey of the real life' outcome in 418 acromegalic subjects. European Journal of Endocrinology 2007157 399-409.

10 Brabant G, von zur Muhlen A, Wuster C, Ranke MB, Kratzsch J, Kiess W, Ketelslegers JM, Wilhelmsen L, Hulthen L, Saller B, Mattsson A, Wilde J, Schemer R, Kann P \& German KIMS Board. Serum insulin-like growth factor I reference values for an automated chemiluminescence immunoassay system: results from a multicenter study. Hormone Research 200360 53-60.

11 Webb SM, Prieto L, Badia X, Albareda M, Catala M, Gaztambide S, Lucas T, Paramo C, Pico A, Lucas A, Halperin I, Obiols G \& Astorga R. Acromegaly Quality of Life Questionnaire (ACROQOL) a new health-related quality of life questionnaire for patients with acromegaly: development and psychometric properties. Clinical Endocrinology 200257 251-258.

12 Badia X, Webb SM, Prieto L \& Lara N. Acromegaly Quality of Life Questionnaire (AcroQoL). Health and Quality of Life Outcomes 2004 2713.

13 Webb SM. Quality of life in acromegaly. Neuroendocrinology 2006 $83224-229$.

14 Rowles SV, Prieto L, Badia X, Shalet SM, Webb SM \& Trainer PJ. Quality of life (QOL) in patients with acromegaly is severely impaired: use of a novel measure of QOL: acromegaly quality of life questionnaire. Journal of Clinical Endocrinology and Metabolism $2005903337-3341$.

15 Webb SM, Colao A, Caron P, Carvalheiro M, Ertürk E, PokrajacSimeunovic A, Schopohl J, Tsagarakis S, Pearson V, Badia X, Caglio S \& Vincenzi B. A European prospective real-life observational study of Quality of Life in patients with acromegaly. Endocrine Abstracts. 8th European Congress of Endocrinology 2006 11 OC20.

16 Orme SM, McNally RJ, Cartwright RA \& Belchetz PE. Mortality and cancer incidence in acromegaly: a retrospective cohort study. United Kingdom Acromegaly Study Group. Journal of Clinical Endocrinology and Metabolism 199883 2730-2734.

17 Ayuk J, Clayton RN, Holder G, Sheppard MC, Stewart PM \& Bates AS. Growth hormone and pituitary radiotherapy, but not serum insulin-like growth factor-I concentrations, predict excess mortality in patients with acromegaly. Journal of Clinical Endocrinology and Metabolism 200489 1613-1617.

18 Kauppinen-Makelin R, Sane T, Sintonen H, Markkanen H, Valimaki MJ, Loyttyniemi E, Niskanen L, Reunanen A \& Stenman UH. Quality of life in treated patients with acromegaly. Journal of Clinical Endocrinology and Metabolism 200691 3891-3896.

19 Paisley AN, Rowles SV, Roberts ME, Lee C, Webb SM \& Trainer PJ. The use of ACROQOL to quantify changes in QOL with treatment of acromegaly. Abstract for the Endocrine Society, 2004 P2-428.

20 Trepp R, Everts R, Stettler C, Fischli S, Allemann S, Webb SM \& Christ ER. Assessment of quality of life in patients with uncontrolled vs. controlled acromegaly using the Acromegaly Quality of Life Questionnaire (AcroQoL). Clinical Endocrinology 200563 103-110.

21 Webb SM \& Badia X. Quality of life in growth hormone deficiency and acromegaly. Endocrinology and Metabolism Clinics of North America 200736 221-232.

22 Giustina A, Barkan A, Casanueva FF, Cavagnini F, Frohman L, Ho K, Veldhuis J, Wass J, Von Werder K \& Melmed S. Criteria for cure of acromegaly: a consensus statement. Journal of Clinical Endocrinology and Metabolism 200085 526-529.

23 Biermasz NR, Van Thiel SW, Pereira AM, Hoftijzer HC, van Hemert AM, Smit JW, Romijn JA \& Roelfsema F. Decreased quality of life in patients with acromegaly despite long-term cure of growth hormone excess. Journal of Clinical Endocrinology and Metabolism 200489 5369-5376.

24 Hua SC, Yan YH \& Chang TC. Associations of remission status and lanreotide treatment with quality of life in patients with treated acromegaly. European Journal of Endocrinology $2006 \mathbf{1 5 5}$ 831-837.

25 Trainer PJ, Drake WM, Katznelson L, Freda PU, Herman-Bonert V, van der Lely AJ, Dimaraki EV, Stewart PM, Friend KE, Vance ML, Besser GM, Scarlett JA, Thorner MO, Parkinson C, Klibanski A, Powell JS, Barkan AL, Sheppard MC, Malsonado M, Rose DR, Clemmons DR, Johannsson G, Bengtsson BA, Stavrou S, Kleinberg DL, Cook DM, Phillips LS, Bidlingmaier M, Strasburger CJ, Hackett S, Zib K, Bennett WF \& Davis RJ. Treatment of acromegaly with the growth hormone-receptor antagonist pegvisomant. New England Journal of Medicine 2000 342 1171-1177.

Received 31 May 2007

Accepted 11 July 2007 